\title{
A Brief History of Undergraduate Mathematics between 1960 to Present in the United States
}

\author{
Liying Huang ${ }^{1, a}$ \\ ${ }^{1}$ School of Physical Science, University of California, Irvine, CA 92697, The United States \\ a1304351712@qq.com
}

Keywords: History, United States, Undergraduate Mathematics

\begin{abstract}
Mathematics, as an undergraduate major, has been through lots of reforms and evolution to become the major as people see today. This paper will discuss about the development of mathematics as an undergraduate major from 1960 to present by analyzing the reasons for the change of the enrollment rate and the progress that the mathematical associations made. Looking through the whole history of undergraduate mathematics program, it was first established in the early 1700s as a training for brain, developed quickly from 1960s to 1970s because of the stimulation of the space race, experienced the depression from 1970s to 1980s due to the poor teaching quality and finally progressed and kept the stable development until present.
\end{abstract}

\section{Introduction}

According to the Oxford dictionary, mathematics is " the abstract science of number, quantity, and space. Mathematics may be studied in its own right (pure mathematics), or as it is applied to other discipline such as physics and engineering." People use math everywhere at anytime because it's tightly related to their lives: people need math when they trade, when they write codes, when they design clothes and when they...etc. Mathematics, as an undergraduate major, has been through lots of reforms and evolution to become the major as people see today. The first math curriculum offered by colleges appeared in the early 1700s, however, at that time, Alan Tucker mentioned that people studied mathematics as a "classical training of the mind" instead of as the "language of science and engineering it is today" [1]. They did not pay much attention to the use of mathematics as a practical science: the most common course "Calculus", which provides a framework for modeling systems, had not entered the college curriculum until the late 1800s. But mathematics had changed a lot during the last 200 years. It flourished from 1960 to 1970 due to the "space race" event. People in the United States considered studying mathematics as a great honor and a great opportunity to fight against the Soviet Union, and also, the change of the college curriculum turned mathematics to a different career focus such as computer programing, which attracted the young generations. However, after 1970, the fever of mathematics decreased sharply because of the poor teaching quality as Alan H. Schoenfeld, who is a professor in UC Berkley and researches on mathematical education, mentioned in $A$ brief biography of calculus reform. To arouse people's interests in mathematics again, the mathematics associations started the calculus reform movement and led the instructors to concentrate more on showing the examples to students and helping students to engage more in classes. Hence the enrollment rate of mathematics stayed constant over the last forty years.

Some previous literature studied the development of mathematical education in the United States. For example, Elaine Seymour, who is a evaluator of SMET(Science, Mathematics, Engineering, and Technology) undergraduate education, concluded the concerns, changes and improvements of SMET in Tracking the Processes of Change in US Undergraduate Education in Science, Mathematics, Engineering, and Technology. The "overall adequacy" of the precollege math education arouses people's attention since the students in the United States ranked the lowest in TIMSS (the third international mathematics and science study) among 46 countries in 1997. Hence people desired reforms, and the reform activities had improved the teaching quality, and the competence of students [2]. And David Klein had written A Brief History of American K-12 mathematics education in the $20^{\text {th }}$ 
century, which showed the education of mathematics in primary school and middle school shifted from "teacher directed instruction" to the "child discovery learning". He also mentioned the popular views of progressive math education in different periods: people struggled to both satisfy content and pedagogy [3].

However, there are only few researches specifically focusing on the history of undergraduate mathematics. So, to bridge the gap, this paper discusses the development of mathematics as an undergraduate major from 1960 to present by analyzing the reasons for the change of the enrollment rate and the progress that the mathematical associations made. To provide solid evidence, this essay collected the data from CBMS (Conference Board of Mathematical Science) and NSF( National Science Foundation), the course offering from the CUPM (Committee on the Undergraduate Program Mathematics) and the teaching guidance from NCTM ( National Council of Teacher of Mathematics).

\section{The bloom of mathematics (1960-1970)}

The golden age for the mathematics major is from 1960s to 1970s. According to the CBMS (Conference Board of Mathematical Science) survey [4], incoming students who were interested in mathematics major reached "the largest fraction", which was 5\%, in the early 1960 s and so did the graduated numbers for bachelor's degree, which was around $4 \%$.

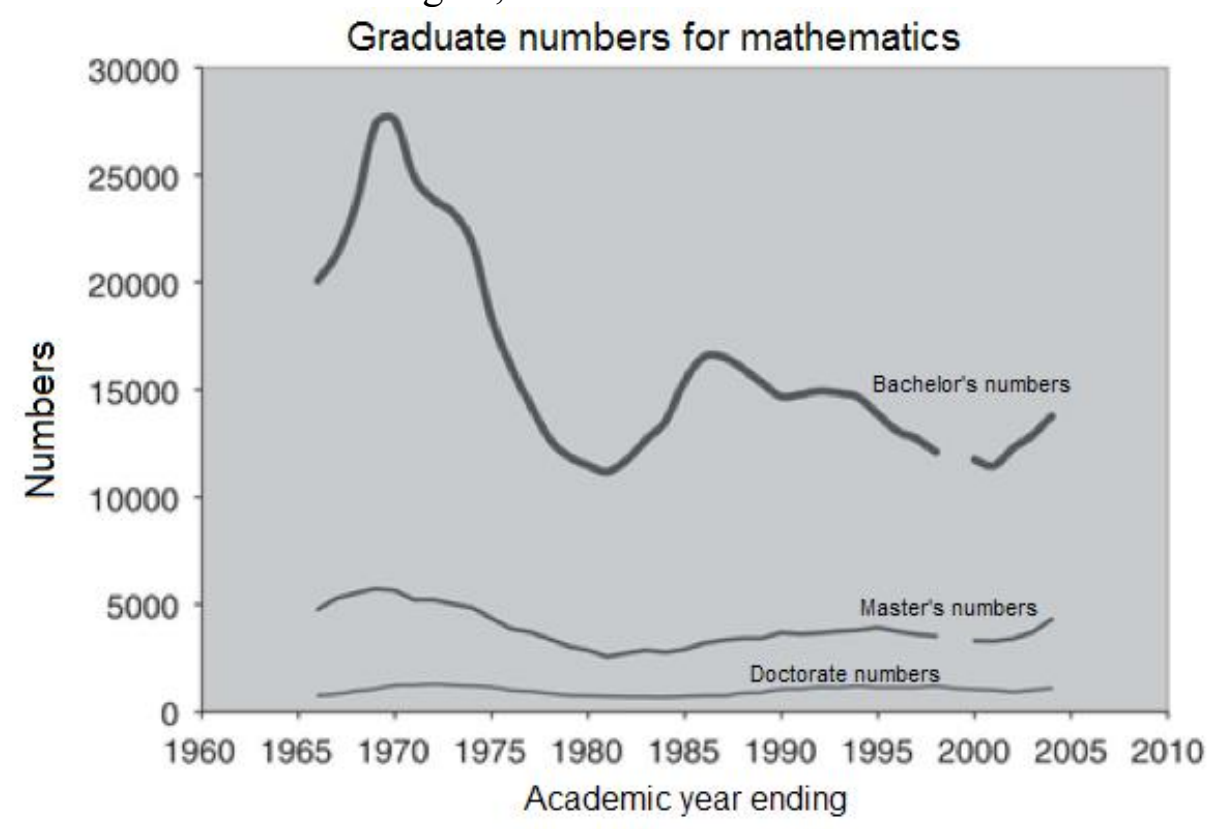

Figure 1 The graduation numbers from 1966 to 2004 in the United States[5]

Also, Figure 1 is a graphic statistic from the National Science Foundation [5], and people can clearly see that the number of mathematical bachelor's degrees increased sharply in the period from 1960 s to 1970 s and it reached its peak in the 1970. One of the most important reasons for this rise is the space event: the first satellite in the world was launched into the space by the Soviet Union in 1957. In the article "The New New Math": Two Reform Movement in Mathematics Education, Terese A. Herrera and Douglas T. Owens pointed out that people in the United States realized that they were "behind in the world scene of technology and military power" [6]. The launch of the Sputnik not only loosened the purse strings of the American government to pay more on the space technology, but also pushed the young generation of America to study Mathematics. As a major that played a key role in the space race, mathematics attracted a large number of young people because they wanted to be the heroes who may fight back against the Soviet Union. One substantial phenomenon was that the mathematics Bachelor's degree at least doubled from the early 1950s to 1060s (CBMS).

In addition to the efforts made by individuals, the mathematical institutions in the United State began to consider whether the mathematics curriculum in the collage is adequate because they lost in 
the first "space battle" with Soviet Union. Due to the space fever, the committee on the Undergraduate Program mathematics (CUPM), which was established in 1953 to modernize the undergraduate mathematics curriculum, was under great pressure. In 1965, CUPM published $A$ General Curriculum in Mathematics for Colleges (GCMC) as a model for a mathematics curriculum. GCMC separated the courses to two parts: the lower division and the upper division. The lower division suggested Calculus, Probability, and Linear Algebra to take care of the general use of math so that other students who preferred to physics, economics or engineering, can also use this curriculum. The upper division suggested Algebraic Structures, Statistics, Numerical Analysis, Geometry, Applied Mathematics, Real Variable Theory, Complex analysis, and Computer Science, which focus more on the theoretical direction of mathematics. The concentration of mathematics major had changed to a more theoretical direction, because of "the success of pure mathematicians in war" [1]. Basically, before 1960s, the career focus in mathematics were the math teacher or the actuary, while after 1960s, the theoretical courses provided a strong basis for the doctoral study and the industrial careers such as computer programming. And the GCMC took off the one-year course such as elementary function and polynomials, which could be prepared and studied in the high school, to make the curriculum more efficient and effective. W.L Duren, the chairman of the CUPM wrote, although the program is minimal, its purpose is to serve a "basis" for the upcoming advanced programs "whenever and whenever these are feasible" in GCMC [7]. GCMC did improve the sequence of mathematics: whether they were mathematics majors or not, students could get benefits from it.

\section{Depression and solution (1970s to present)}

The interest of mathematics had dropped dramatically in the 1970s. According to the data from CBMS and National Science Foundation (NSF), the percentage of freshmen interested in the mathematics major declined from $4.5 \%$ in 1966 to $3.2 \%$ in 1970 to $1.1 \%$ in 1975 , and never rose above $1.5 \%$ again [5]. Also the figure 1 on the first part, the enrollment rate of mathematics declined from around 28000 to 11000 from 1970 to 1980. One of the reasons for the decline of the math fever may be the poor teaching quality in the university. In the early $1950 \mathrm{~s}$, most university faculty members who had doctoral degrees were supposed to teach the undergraduate students and treat teaching as the first priority. However, in 1970, the research became the primary focus. The consequence of this change as Tucker pointed out in public universities, is that the mathematics of the freshmen was "typically" instructed by the graduate students, or by "faculty with supporting TA led recitations" in the large classes [1]. The teaching quality decreased because of the inexperienced instructors and the heavy teaching load (up to 15 hours per week). Also the disadvantages of the courses and the teaching methods gradually showed up in these ten years. Alan H. Schoenfeld emphasized that there was a "growing discontent with the result of calculus instructions" [8]. Sometimes students just couldn't "get" the knowledge. There were also some complaints about the superficial knowledge in calculus, and the narrow range of the mathematical techniques. The increasing amount of dissatisfactions arose the attention of the mathematics departments.

The math departments and associations are worried that the interest of undergraduate freshmen might switch to other majors, for example, the statistics major, so that they had changed their focus. For example, in the early 1970s, CUPM concentrated on the preparation for the doctoral study. Due to the sharp decline in mathematics major, it changed its focus on the undergraduate students who might choose math as their majors. It also made a report called Recommendations for a General Mathematical Science Program in 1981, which suggested the mathematical curriculum designed for the average students. However, RomDavid M. Bressoud wrote, "Initially, this report had very little impact" [9] (What's Been Happening to undergraduate Mathematics) because it was not formally published until 1989.

The pressure for attracting more undergraduate students led to the calculus reform, which aimed to improve the teaching quality and fulfill the expectations of students for math in the late 1980s. It was started by the publication of Curriculum and Evaluation Standards for School Mathematics, which 
was created by the National Council of Teacher of Mathematics (NCTM). Bressoud mentioned that, "one of the most simplest yet most important insights" in the calculus reform movement is that instructors must supply "examples, practice and evaluations" that used different representations of functions, for instance, the graphs, tables, or the symbolic formulas to help students have a better approach to the knowledge. Before the movement, students were required to know these kinds of concepts, but teachers would not give them enough practice on each representation of functions. The calculus reform rendered students understood the knowledge deeper because they could get enough practice now. Also, during the calculus movement, teachers were more likely to use technology (graphing calculators and computer) to present the class. Some courses became the laboratory courses that students could build models in by using the computer algebra system. Schoenfeld showed the situations in "calculator-based" course, "problem driven" modeling course, the "laboratory" course, and the " activity based" course. He emphasized that, "One major theme is engagement", once the students worked on projects by themselves, they would have deeper impression about the knowledge learned in class [9].The engagement enabled the students to concentrate more, learn more, and gain more interest. Calculus reform certainly "helped draw people in to math who might not have been there otherwise" (Ewing, Towards excellence, part II) [10]. They were no longer stuck in the theoretical knowledge. The reports from Tucker and Leitzel indicated that in spring 1994, there were $68 \%$ of responding mathematics departments (total was 1048) testified that "at least modest calculus reform efforts" were "currently underway" and $22 \%$ of them indicated "major reform" [1].

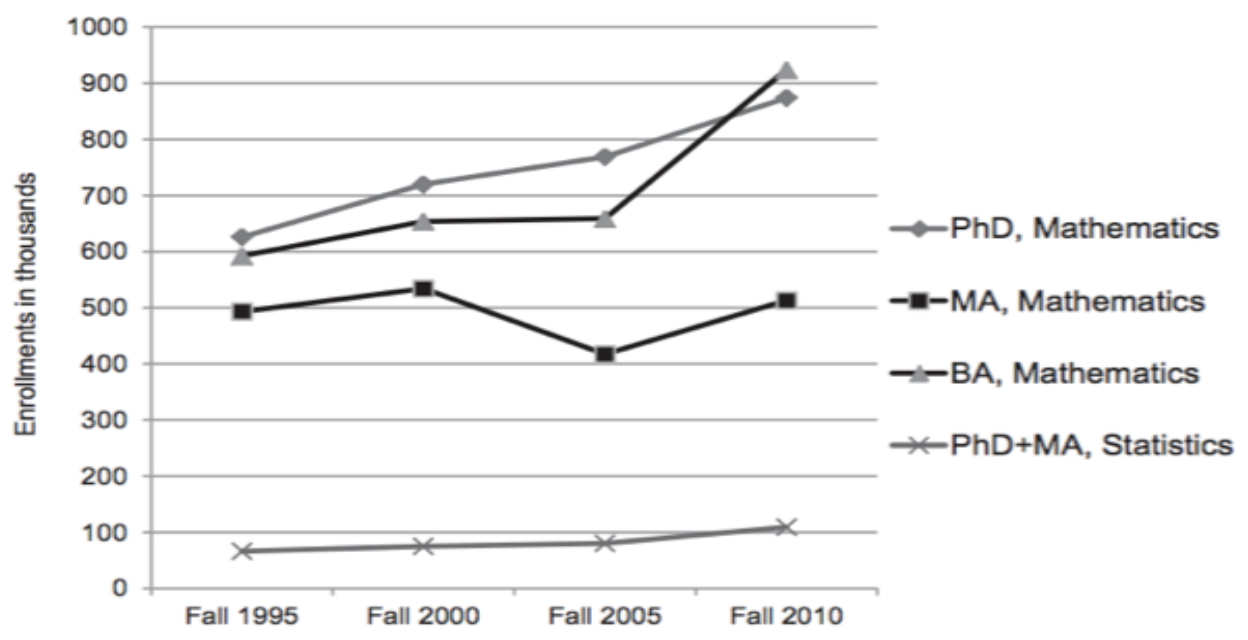

Figure 2 Undergraduate enrollment (in thousands) by type of department in fall 1995, fall 2000, fall 2005, and fall 2010

The progress of the reforms was not assured, but it made sure the constant enrollment tread over the last 40 years. As you can see, Figure 2 is a statistic of the undergraduate enrollment from fall 1995 to fall 2010. It showed that the Bachelor's degree of mathematics has grown in a stable way: there are nearly 600,000 undergraduate students got the Bachelor's degree in fall 1995, and in fall 2010, there are nearly 900,000 students got the degree. Also, according to 2010 CBMS Survey of Undergraduate program, "the total national enrollment in mathematics courses in fall 2010 was roughly 1,971,000, up $23 \%$ from 1,607,000 in fall 2005" [11], mathematics has already become one of the most important courses and majors in the university.

\section{Conclusions}

To draw a conclusion, looking through the whole history of undergraduate mathematics program, it was first established in the early 1700 s as a training for brain, developed quickly from 1960s to 1970s because of the stimulation of the space race, experienced the depression from 1970s to 1980s due to the poor teaching quality and finally progressed and kept the stable development until present. There are lots of reforms in undergraduate mathematics, and the math association tried their best to improve the curriculum and the teaching quality to attract more students. 


\section{References}

[1] Tucker, A. (2013). The history of the undergraduate program in mathematics in the United States. American Mathematical Monthly, 120(8), 689-705.

[2] Seymour, E. (2002). Tracking the processes of change in US undergraduate education in science, mathematics, engineering, and technology. Science Education, 86(1), 79-105.

[3] Klein, D. (2003). A brief history of American K-12 mathematics education in the 20th century. Mathematical cognition, 175-259.

[4] Jewett, J. \& Lindquist, C, B. (1972). CBMS survey reports (Rep.). CBMS.

[5] National Science Foundation, S\& E Degrees: 1966-2006, Report 08-321, Washington, DC, 2008.

[6] Herrera, T. A., \& Owens, D. T. (2001). The" new new math"?: Two reform movements in mathematics education. Theory into Practice, 40(2), 84-92.

[7] Duren, W. L. (1965). A general curriculum in mathematics for colleges. The American Mathematical Monthly, 72(8), 825-831.

[8] Schoenfeld, A. H. (1995). A brief biography of calculus reform. UME trends, 6(6), 3-5.

[9] Bressoud, D. M. (2001). What's been happening to undergraduate mathematics. J. Chem. Educ, 78(5), 578.

[10] Ewing, J. (Ed.). (1999). Towards excellence: Leading a doctoral mathematics department in the 21 st century. Amer Mathematical Society.

[11] Richelle Blair, Ellen E. Kirkman, \& James W. Maxwell (2010). CBMS survey reports (Rep.). CBMS. 